\title{
Correction to: Occlusion of left atrial appendage affects metabolomic profile: focus on glycolysis, tricarboxylic acid and urea metabolism
}

\author{
K. Sattler ${ }^{1} \cdot$ M. Behnes ${ }^{1} \cdot$ C. Barth ${ }^{1} \cdot$ A. Wenke ${ }^{1}$ - B. Sartorius ${ }^{1} \cdot$ I. El-Battrawy ${ }^{1} \cdot$ K. Mashayekhi $^{2} \cdot$ J. Kuschyk $^{1}$.

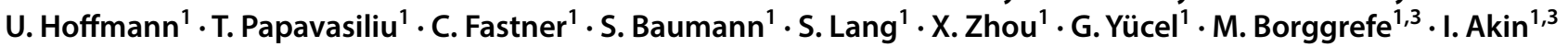

Published online: 12 January 2018

(c) The Author(s) 2018. This article is an open access publication

\section{Correction to: Metabolomics (2017) 13:127 https://doi.org/10.1007/s11306-017-1255-2}

The article Occlusion of left atrial appendage affects metabolomic profile: focus on glycolysis, tricarboxylic acid and urea metabolism, written by K. Sattler, M. Behnes, C. Barth, A. Wenke, B. Sartorius, I. El-Battrawy, K. Mashayekhi, J. Kuschyk, U. Hoffmann, T. Papavasiliu, C. Fastner, S. Baumann, S. Lang, X. Zhou, G. Yücel, M. BorggrefeI, Akin, was originally published Online First without open access. After publication in volume [13], issue [11], Citation ID [127] the author decided to opt for Open Choice and to make the article an open access publication. Therefore, the copyright of the article has been changed to $($ C) The Author(s) [2017] and the article is forthwith distributed under the terms of the Creative Commons Attribution 4.0 International License (http://creativecommons.org/licenses/ by/4.0/), which permits use, duplication, adaptation, distribution and reproduction in any medium or format, as long as you give appropriate credit to the original author(s) and the source, provide a link to the Creative Commons license and indicate if changes were made. The original article has been corrected.

Open Access This article is distributed under the terms of the Creative Commons Attribution 4.0 International License (http://creativeco mmons.org/licenses/by/4.0/), which permits unrestricted use, distribution, and reproduction in any medium, provided you give appropriate credit to the original author(s) and the source, provide a link to the Creative Commons license, and indicate if changes were made.

The online version of the original article can be found under https ://doi.org/10.1007/s11306-017-1255-2.

M. Behnes

Michael.Behnes@umm.de

1 First Department of Medicine, Faculty of Medicine Mannheim, University Medical Centre Mannheim (UMM), University of Heidelberg, Theodor-Kutzer-Ufer 1-3, 68167 Mannheim, Germany

2 Clinic of Cardiology and Angiology II, Universitäts-Herzzentrum Freiburg-Bad Krozingen, Bad Krozingen, Germany

3 DZHK (German Center for Cardiovascular Research), Partner Site, Heidelberg-Mannheim, Mannheim, Germany 